\title{
Simpler/better healthcare by integrating payers and practitioners
}

\section{Measuring and Managing outcomes guides the way}

\section{The need; why reform healthcare?}

Ans.: Because we, as a Nation, are now spending:

a. Nearly $\$ 10 \mathrm{~K}$ annually per capita in the U.S. on the total cost of healthcare.

b. This is approximately one dollar for every five of our gross domestic product.

c. Also, the cost of care is rising faster than the rate of inflation.

The above findings derive from the Commonwealth Fund who sponsors research on ways to improve healthcare in the U.S. The Fund's most recent comparison of healthcare in the industrialized world reveals that the U.S. system ranks last in most categories and was above an 11-country average in only one.

Regardless of how developed countries pay for healthcare, it is noteworthy that the top three - the United Kingdom, the Netherlands, and Australia - share some organizational and psycho-social features, which are as follows:

a. They all try to make sure that most citizens are in the same or similar risk pool as those with health insurance coverage; i.e., they are "community" as opposed to "experience" rated health plans.

b. In that pool, everyone has access to a similar offering of health benefits, regardless of things like "age" and/or "health status."

c. They all have ways to ensure that no one is left out just because they can't afford to pay. 1

A survey with compelling findings about the costs of care, variation in quality, and disappointment in processes and outcomes is the NEJM Catalyst New Marketplace survey (2017) speaks to runaway healthcare costs in the U.S. and not having much benefit to show from the expenditures. In addition, special areas covered by this survey include, but are not limited to: risk-based payment arrangements, payer-provider integration, incentives, incentive alignment and how well or poorly aligned payers and providers are doing in the pursuit of 'value-based care.'

\section{Data heals (If it is Actionable)}

We learn that reforming healthcare is difficult, irrespective of organizational type and whether they have robust information systems, case management or even a data analytic shop, in house. A reliable way to begin addressing the cost, quality and access to care is to get actionable data into the "hands of providers at the point of care"; 4 get practitioners and their staffs to translate these data into information, and then incorporate such salient information into their workflow. ${ }^{2}$ Analytics for Payer-Provider Collaboration." NEJM Catalyst Nov.

\author{
Opinion \\ Volume 8 Issue I - 2018 \\ Jeffrey Gene Kaplan \\ Adjunct Clinical Assistant Professor of Pediatrics, USA \\ Correspondence: Jeffrey Gene Kaplan, Adjunct Clinical \\ Assistant Professor of Pediatrics, USA, \\ Email drjgkaplan@gmail.com \\ Received: January 30, 2018 | Published: February 26, 2018
}

2017. (See, especially "Barriers and Opportunities for Producing Better Outcomes.") If we don't become better informed, we will have to pay providers less or charge patients more the doctor's bill should be based on the complexity. ${ }^{3}$ of the patient's problems and the time spent managing the patient according to the Centers for Medicare $\&$ Medicaid Services (CMS). They say "add up the estimated time for every appointment, and check that the total does not exceed the doctor's recorded office hours that day. The patient's complaints, ICD10 codes and medication list can be used to determine complexity." David L. Keller DL. "MACRA will not save money." Medical Economics, November 20, 2017 Caveat (Addendum).

\section{Timely Information}

Any competent transformation in our health care system would have to address the issue of accountability, especially in terms of costeffectiveness, cost-benefit, and/or variation (in efficiency or quality) in clinical processes, and outcomes.

For example, although they care for less than $1 \mathrm{fifth}$ of the eligible US population, accountable care organization (ACO) models are promising and they come with plenty of medical management tools:

I. Non-prescriptive, specialty-derived guidelines

II. Acuity-adjusted clinical process and outcome data that may be translated into clinically meaningful

III. Case management, patient satisfaction, continuity of care, etc. information all of which can be made available at the point of care.

Ganguli I, Ferris TG. "Accountable Care at the Frontlines of a Health System; Bridging Aspiration and Reality." JAMA. Published online December 11, 2017. doi:10.1001/jama.2017.18995

\section{Recommendations for payer practitioner collaboration}

Here are six actions that can be used to achieve and improve collaboration: 
a. Ensure that payer and practitioner (staff) are on the same page and that they are communicating.

Note: a lack of interoperability impedes collaboration within and across organizations.

b. Transition to value-based care rather than fee-for-service (which, by definition is piecework).

Sharing data if not that plus risk. "Focus collaboration around existing value-based agreements, such as bundled payments."

c. Act responsibly, learning to share data as you go along; involve the patient as a partner.

"Where the parties can trustworthily share data, everyone benefits."

\section{d. Based on analytical capability, set realistic expectations.}

"Set short-term realistic goals while making strategic investments in analytics* capabilities."

e. Work together on what matters most: improvement in health.

"Analytics* can be applied for financial and infrastructure improvements, but the biggest goal identified by provider and payer leaders alike lies in clinical quality," especially in healthcare outcomes.

f. Gather data on health, patient satisfaction with healthcare processes and outcomes, not just health care.

Include "EMR and claims data, streams from pharmacies, labs, and other nontraditional clinical sources; social needs; genomic data; and .... Personal data." The above six were developed during the 2017 NEJM Catalyst Roundtable Forum on Analytics, sponsored by Deloitte.

*Analytics can be instrumental in effecting change, as well as helping to align incentives

Amy Compton-Phillips, MD, Executive Vice President and
Chief Clinical Officer for Providence St. Joseph Health System, and Care Redesign Theme Leader for NEJM Catalyst, says healthcare transformation requires a strong core of medical practice, less waste, being able to redirect earnings to things that matter the most such as "decreasing the variation in practice... Improving the safety of the care," and other high value outcomes, such as patient satisfaction, efficiency and quality. ${ }^{5}$

\section{Acknowledgment}

None.

\section{Conflict of interest}

None.

\section{References}

1. Michael Smith. Looking Under the Hood of 'Socialized Medicine' Varied approaches in countries outperforming U.S. on healthcare measures. MedPage Today December 04; 2017.

2. Austin Ridgeway. Analytics for Payer-Provider Collaboration. NEJM Catalyst. (See, especially "Barriers and Opportunities for Producing Better Outcomes.), BPO Health Care Partnerships November; 2017.

3. David L, Keller DL. MACRA will not save money. Medical Economics, November 20; 2017.

4. Ganguli I, Ferris TG. Accountable Care at the Frontlines of a Health System; Bridging Aspiration and Reality. JAMA 2018;19(7): 655-656.

5. Rotenstein LS, Huckman RS, Wagle NW. Making Patients and Doctors Happier - The Potential of Patient-Reported Outcomes. $N$ Engl J Med 2017;377(14): 1309-1312. 